Document downloaded from:

http://hdl.handle.net/10251/176380

This paper must be cited as:

Font-Pérez, A.; Borrachero Rosado, MV.; Soriano Martinez, L.; Monzó Balbuena, JM.; Paya Bernabeu, JJ. (2021). Air-void system characterization of new eco- cellular concretes. Journal of Materials in Civil Engineering. 33(5):1-10. https://doi.org/10.1061/(ASCE)MT.1943-5533.0003692

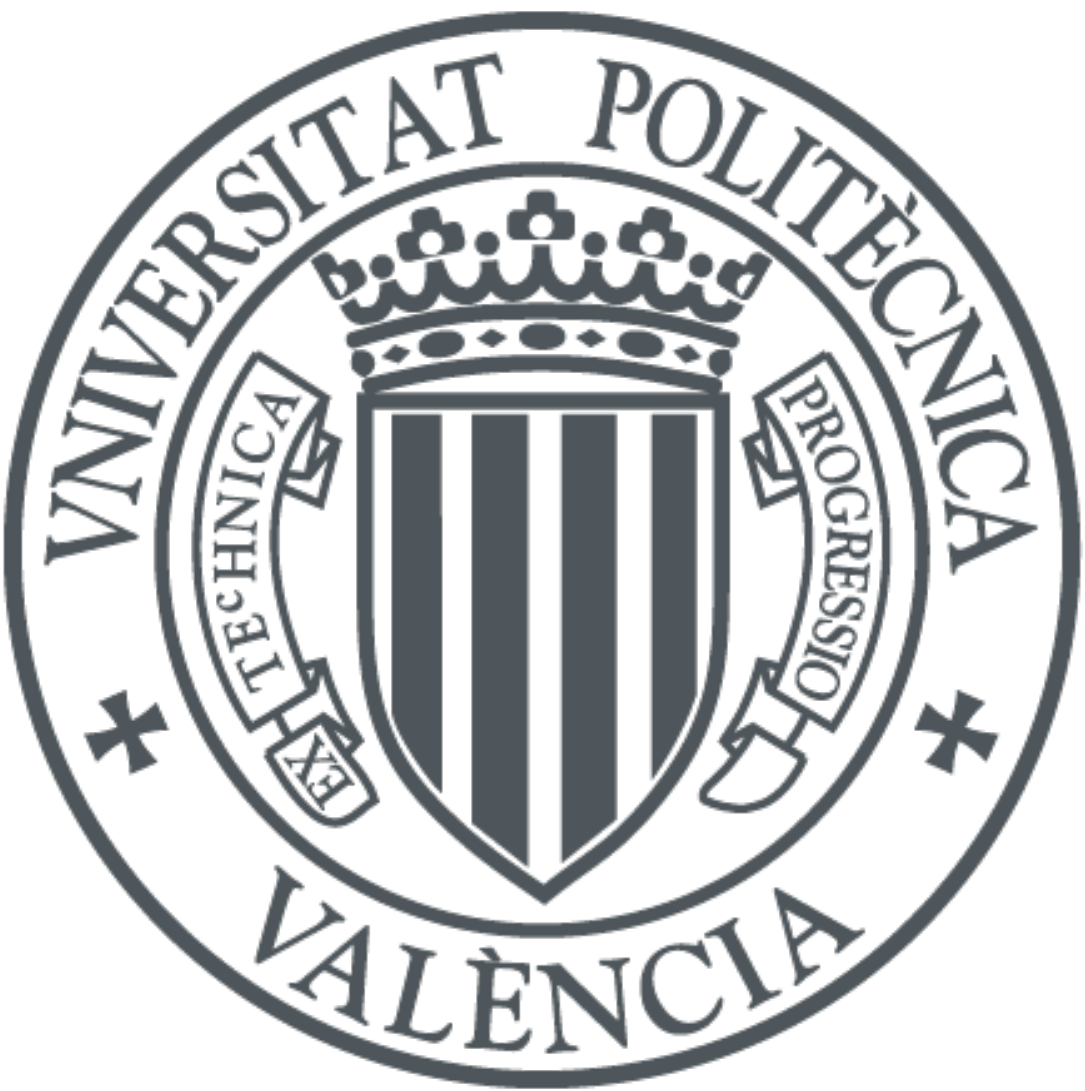

The final publication is available at

https://doi.org/10.1061/(ASCE)MT.1943-5533.0003692

Copyright American Society of Civil Engineers

Additional Information 

9 30

\section{AIR-VOID SYSTEM CHARACTERIZATION OF ECO-CELLULAR CONCRETES}

Alba Font

Ph.D student, alprefon@upvnet.upv.es Universitat Politècnica de València (UPV)

ICITECH - Instituto de Ciencia y Tecnología del Hormigón, Grupo de Investigación en Química de los Materiales (GIQUIMA), Universitat Politècnica de València, València, Spain. María Victoria Borrachero

Ph.D, Professor, vborrachero@cst.upv.es, Universitat Politècnica de València (UPV)

ICITECH - Instituto de Ciencia y Tecnología del Hormigón, Grupo de Investigación en Química de los Materiales (GIQUIMA), Universitat Politècnica de València, València, Spain. Lourdes Soriano

Ph.D, lousomar@upvnet.upv.es, Universitat Politècnica de València (UPV)

ICITECH - Instituto de Ciencia y Tecnología del Hormigón, Grupo de Investigación en Química de los Materiales (GIQUIMA), Universitat Politècnica de València, València, Spain. José Monzó

Ph.D, Professor, jmmonzo@cst.upv.es, Universitat Politècnica de València (UPV)

ICITECH - Instituto de Ciencia y Tecnología del Hormigón, Grupo de Investigación en Química de los Materiales (GIQUIMA), Universitat Politècnica de València, València, Spain. Jordi Payá - Corresponding author

Ph.D, Professor, jjpaya@cst.upv.es; Tel.: +34 963877564

ICITECH - Instituto de Ciencia y Tecnología del Hormigón, Grupo de Investigación en Química de los Materiales (GIQUIMA), Universitat Politècnica de València, València, Spain. (2)

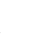
. 
Cellular concrete is an alternative to conventional concrete as a low-density and high-insulating building material. The eco-cellular concretes (ECC) based on the geopolymer technology have been recently introduced by the scientific community. A form of ECC was herein studied, in which the fluid catalytic cracking residue and the blast furnace slag were employed as precursors, the rice husk ash was utilized as an alternative silica source in the activator and the aerating reagent was replaced with recycled aluminum foil. Field emission scanning electron microscopy, optical microscopy and the ImageJ software were employed to characterize the void distribution. Bulk density and porosity were determined by hydric tests. The results revealed that lowest densities without strength loss were obtained when the cementing matrix had a homogeneous void-system: similar spacing between pores, narrow size ranges and non interconnected pores. A relation between open/close porosity with both density and thermal conductivity was established.

keywords: cellular concrete, blast furnace slag, fluid catalytic cracking residue, rice husk ash, thermal insulation, pore system.

\section{Abbreviations:}

TCC: Traditional cellular concrete

GCC: Geopolymer cellular concrete

ECC: Eco-cellular concrete

FCC: Fluid catalytic cracking residue

BFS: Blast furnace slag

RHA: Rice husk ash

RAF: Recycled aluminum foil

A: Commercial aluminum powder

\section{INTRODUCTION}

Traditional cellular concrete (TCC) is a Portland cement-based paste or mortar (with sand or fly ash) to which a controlled aerating agent (commonly aluminium powder) is added. This hence results in a lightweight high-insulation material with medium-low mechanical behavior (Ramamurthy, Kunhanandan Nambiar, and Indu Siva Ranjani 2009). Compared to other construction materials, a costeffective solution, better performance and faster construction are achieved when cellular concrete is used. This material is commonly employed in masonry units for floors, roofs and walls (Bremner et al. 1997). 
Dolton and Hannah(Dolton and Hannah 2006) presented case studies of cellular concrete applications in cold climates, and highlighted the easy application in an insulation solution as shallow utilities, pipeline and tank, frost-protected shallow foundations or below-ground grouting voids, among others.

Hence density, compressive strength and thermal insulation must be assessed and controlled to obtain good-performing cellular concretes. These properties are directly related with their void system configuration (volume, mean diameter and distribution of formed internal air pores) (Ramamurthy, Kunhanandan Nambiar, and Indu Siva Ranjani 2009). Porosity and strength are related to the empirical models proposed by Narayanan and Ramamurthy(Narayanan and Ramamurthy 2000c) and by Kearsley and Wainwright(Kearsley and Wainwright 2001). A concise study was done by Nambiar and Ramamurthy(Nambiar and Ramamurthy 2007), which established a direct relationship between pore parameters (volume, size and spacing) and the bulk density and strength of traditional cellular concretes. These authors reported that pore shape did not influence final cellular concrete properties. Moreover, a linear relation between thermal conductivity and dry bulk density was reported by Zhang et al. (Zhang et al. 2015), and closed porosity with thermal conductivity correlations were also demonstrated by Topçu et al. (Topçu and Uygunoğlu 2007). Wee et al. (Wee et al. 2006) revealed that optimal air content was enclosed in the traditional cellular concretes matrix to obtain a homogeneous air-void distribution and, consequently, low densities without strength loss. These authors showed that more air entrapped caused mechanical behavior to worsen because of an interconnection of bigger sized pores. Othuman and Wang (Othuman and Wang 2011) reported the strong influence of pore size distribution in the thermal conductivity and physical properties of prediction models for cellular concrete manufacturing. Recently, the same conclusion was reached by Almalkawi et al. (Almalkawi et al. 2018), who confirmed that a well-organized air-bubbles system in a matrix with a more spherical shape would avoid internal water circulation, which would give high compressive strength and low thermal conductivity.

Void system research works have mainly utilized scanning electron microscopy (SEM), mercury intrusion porosimetry (MIP), gas permeability, X-ray computer tomography or optical microscopy (Akthar and Evans 2010; Almalkawi et al. 2018; Nambiar and Ramamurthy 2007; Narayanan and Ramamurthy 2000a; Yang et al. 2014). In recent research, the measurement of void parameters (shape, size, volume and distribution) has been carried out by 2D image analysis processing and using computer software, such as Avizo (Ducman and Korat 2016), Photoshop (Panesar 2013) or ImageJ (Esmaily and 
Nuranian 2012). The bulk density and porosity of cellular concretes have been traditionally tested by hydric tests (Colangelo et al. 2018; Pinilla Melo, Sepulcre Aguilar, and Hernández Olivares 2014). It is well-known that the scientific community currently focuses on developing new materials that offer a healthy and environmental-friendly alternative to conventional ones. TCC is $60 \%$ to $70 \%$ based on Portland cement (OPC). The environmental impact of OPC and its non renewable raw materials consumption have led the scientific community to investigate new alternatives.

The application of alkali activation or geopolymers technology to cellular concrete manufacturing has rapidly gained importance in the last few years. Many authors have published works in which greener geopolymer cellular concretes (GCCs) were developed and analyzed (Bai et al. 2016).

Fly ash and blast furnace slag (BFS) have been the most widely used precursors to new GCCs development. The combination of Class F fly ash and blast furnace slag has been employed as precursors by Zang et al. (Zhang et al. 2015) to develop GCC activated by sodium hydroxide (NaOH) and sodium silicate dissolution. The best results were obtained for the specimen with $30 \%$ BFS and $70 \%$ fly ash, which respectively yielded compressive strength, density and thermal conductivity of $3 \mathrm{MPa}, 720 \mathrm{~kg} / \mathrm{m}^{3}$ and $0.15 \mathrm{~W} / \mathrm{mK}$ (after a curing treatment consisting in: firstly $24 \mathrm{~h}$ at $40^{\circ} \mathrm{C}$, and then 27 days under ambient conditions). More recently, Stolz et al. (Stolz, Boluk, and Bindiganavile 2018) also studied the physical characteristics of GCC systems based on fly ash activated by $\mathrm{NaOH}$ and sodium silicate solution, and by incorporating glass fibers into mixes to improve mechanical behavior. Specimens were cured at room temperature, and densities between 1000 and $1400 \mathrm{~kg} / \mathrm{m}^{3}$ and compressive strengths from 3 to 9 MPa were obtained. Esmaily and Nuranian (Esmaily and Nuranian 2012) presented non autoclaved GCCs by employing BFS activated with $\mathrm{NaOH}$ and sodium silicate. Specimens were compared depending on curing temperature $\left(70^{\circ} \mathrm{C}, 78^{\circ} \mathrm{C}, 87^{\circ} \mathrm{C}\right)$. The best results were obtained for the GCCs cured at $87^{\circ} \mathrm{C}$, which yielded a wet density and compressive strength of $946 \mathrm{~kg} / \mathrm{m}^{3}$ and $3.7 \mathrm{MPa}$, respectively. The conducted experimental work included void system characterization, which determined the mean diameter of samples to be $608 \mu \mathrm{m}$. The authors concluded that the pore structure more strongly influenced compressive strength than curing treatment.

Xuan et al. (Xuan, Tang, and Poon 2019) introduced the use of municipal solid waste incineration bottom ash (MSWIBA) combined with waste-glass powder (WGP) as a precursor. With a $20 \%$ of WGP, GCCs were obtained that fell within the ranges of $494-1295 \mathrm{~kg} / \mathrm{m}^{3}, 0.9-10.4 \mathrm{MPa}$ and $0.14-0.38 \mathrm{~W} / \mathrm{mK}$. That 
research work showed alternative materials with a wider internal voids size distribution than TCCs (within the 0.02-3.0 $\mathrm{mm}$ range), but no correlation with the obtained physical characteristics was made. In a recent research work, Font et al.(Font et al. 2018) presented a novel alternative cellular concrete development, where the functional properties and carbon footprint were assessed. Three cellular systems were studied: i) TCC based on OPC and commercial aluminum powder (A); ii) GCC by using fluid catalytic cracking residue (FCC) or BFS as a precursor, activated by a traditional activating solution ( $\mathrm{NaOH}$, plus commercial waterglass (WG), i.e., sodium silicate), and aerated by means recycled aluminum foil (RAF); iii) Eco-cellular concretes, with a similar composition to GCC, where commercial waterglass was replaced with rice husk ash (RHA). The physical properties of the developed cellular concretes are summarized in Table 1.

The authors carried out a comparative carbon footprint calculation with the three cellular systems (TCC, GCC and ECC) by considering the associated emissions of the components and the manufacturing process. By taking the total TCC carbon footprint as a reference, the following conclusions were reached: i) the use of geopolymer technology and the aluminum source replacement (GCC systems) allows to reduce the total $\mathrm{CO}_{2}$ emissions by $24 \%$ in the FCC system and by $48 \%$ in the BFS system; ii) when WG was replaced with RHA, these emission was cut by $74 \%$ and $78 \%$ when using FCC and BFS, respectively.

These results were the first evidence for an eco-friendly alternative with acceptable functional properties in its applicability. At this point, a number of research steps are necessary to improve its properties and to manage dose variability effects.

In the present work, the air-void system of the aforementioned developed materials was investigated. Characterization was done by combining several techniques: i) field emission scanning electron microscopy (FESEM), optical microscopy (OM), and the image software analysis were employed to obtain the void size distribution; ii) bulk density and porosity were determined by hydric tests.

The results allowed the comparison of the internal matrix structure formed by gas expansion from the aerating reaction in each material. Relations between the resulting final void-structure and the functional properties of each material were established.

\section{MATERIALS AND METHODS}

Table 2 shows the materials employed in the present investigation and its origin. On the other hand, the chemical composition of the raw materials (OPC, FCC, BFS and RHA) is summarized in Table 3. 
A summary of the materials and the dose selected to manufacture the TCC, GCCs and ECCs in the present study can be observed in the Table 4 .

The mixing process was carried out by means of a paint mixer connected to a power drill AEG SBE705RE model. The sequence to the specimen's manufacture was as follow:

\section{To prepare TCC:}

1. The OPC and A were manually mixed for 2 minutes $=$ solid phase

2. The solid phase was mixed for 180 seconds with water

\section{To prepare GCCs and ECCs:}

1. The precursors were co-milled with the RHA in a ball mill: i) FCC + RAF for 30 minutes, obtaining the solid phase named $\mathrm{FCCR}_{\mathrm{m}}\left(\mathrm{D}_{\text {mean }}=18.43 \mu \mathrm{m}\right)$.and ii) $\mathrm{BFS}+\mathrm{RAF}$ for 20 minutes, obtaining the solid phase named $\mathrm{BFSR}_{\mathrm{m}}\left(\mathrm{D}_{\text {mean }}=26.28 \mu \mathrm{m}\right)$.

2. The alkali dissolution (liquid phase) was shaken by the power drill for 30 seconds.

3. The solid phase was added to the liquid phase and mixed for 180 seconds.

Fresh paste was put in a $4 \times 4 \times 4 \mathrm{~cm}^{3}$ cubic mold (filled up to $50 \%$ of its capacity) and, because of the reaction, the paste volume grew. Consequently, the final volume of the hardened aerated paste exceeded 0.5-1 $\mathrm{cm}$ over the top edge of the mold. After $24 \mathrm{~h}$, this exceeding material was cut with a saw blade before demolding. Then specimens were demolded and kept at room temperature until testing began. The number, mean diameter and distribution of the formed internal air pores were studied by FESEM, $\mathrm{OM}$ and the ImageJ software. A cube $\left(4 \times 4 \times 4 \mathrm{~cm}^{3}\right)$ of each formulation was crushed in a porcelain mortar. A small piece $(7-10 \mathrm{~mm})$ from the inner part of the cube was selected and immersed in acetone for 30 minutes and dried at $65^{\circ} \mathrm{C}$ for 40 minutes. These samples were studied by FESEM. The FESEM micrographs of the carbon-covered samples were taken by an ULTRA 55-ZEISS electron microscope (at magnifications of 100x and 200x), which allows pore section configurations and pore diameters to be measured. Another $4 \times 4 \times 4 \mathrm{~cm}^{3}$ cubic sample was cut into $2 \mathrm{~cm}$-thick slices perpendicularly to the cast face with a diamond rotary saw. The internal $16-\mathrm{cm}^{2}$ surfaces were observed under a Leica S8 APO optical microscope. Pictures were taken with a Leica DFC 420 digital camera and images were processed by the Leica LAS image analysis software. 8x magnifications were selected with a pixel representing 12 microns. Then these cut-off internal $16-\mathrm{cm}^{2}$ surfaces were immersed in a concentrated solution $(0.4 \%$ by volume) of universal dye (color vermilion 780) and universal solvent (302 NC), both from TKROM. To complete pore impregnation, the submerged samples were placed inside a vessel connected to a vacuum 
pump (Fig 1. a). An image of an impregnated surface was taken (Fig 1. b) (two images of each 16- $\mathrm{cm}^{2}$ internal surface per sample). Images were digitized and processed by the ImageJ software. Morphological operations (dilation, erosion, opening, closing and hole filling) to refine the shape of objects, and for the conversion into the binary form, were performed. Pore diameter distribution histograms were obtained by measuring all the pore diameters at the original magnification.

The bulk density and porosity of the cellular concretes were determined by hydric tests, which were done in six cubic samples $\left(4 \times 4 \times 4 \mathrm{~cm}^{3}\right)$ of each cellular concrete (CA, FR, FRR, SR and SRR). Specimens were weighed and the natural density $(\rho)$ was calculated after 7 curing days. Archimedes method was used for bulk density ( $\rho_{\text {bulk }}$ ) calculations (Equation (1) and Equation (2)) by employing still water as a known density liquid $\left(1000 \mathrm{~kg} / \mathrm{m}^{3}\right)$. The cubic samples were weighed after being left to dry for $24 \mathrm{~h}$ in a furnace at $105^{\circ} \mathrm{C}$ to obtain their dry weight values $\left(\mathrm{W}_{\mathrm{dry}}\right)$. Then samples were fully saturated by water immersion for $24 \mathrm{~h}$ and weighed (saturated weight $\left(\mathrm{W}_{\text {sat }}\right)$ ). In the saturation state, specimens were weighed by a hydrostatic balance (submerged weight $\left(\mathrm{W}_{\text {sum }}\right)$ ). To calculate the true density $\left(\rho_{\text {true }}\right)$ (Equation (3)), a Le Chatelier flask with still water was used after crushing $20 \mathrm{~g}$ of each material to obtain the true volume $\left(\mathrm{V}_{\text {true }}\right)$. The total, open and closed porosities $\left(\Phi_{\mathrm{t}}, \Phi_{\mathrm{o}}\right.$ and $\left.\Phi_{\mathrm{c}}\right)$ were obtained by Equations (4), (5) and (6), respectively.

$$
\begin{gathered}
V_{\text {bulk }}=\frac{W_{\text {sat }}-W_{\text {sum }}}{\rho_{\text {water }}} \\
\rho_{\text {bulk }}=\frac{W_{\text {dry }}}{V_{\text {bulk }}} \\
\rho_{\text {true }}=\frac{W_{\text {dry }}}{V_{\text {true }}} \\
\Phi_{t}(\%)=\left(\frac{1-\rho_{\text {bulk }}}{\rho_{\text {true }}}\right) \times 100 \\
\Phi_{o}(\%)=\left(\frac{W_{\text {sat }}-W_{\text {dry }}}{W_{\text {sat }}-W_{\text {sum }}}\right) \times 100 \\
\Phi_{c}(\%)=\Phi_{t}-\Phi_{o}
\end{gathered}
$$

195 Simple linear regression and correlation between density and thermal conductivity (as dependent variables) with bulk density and porosity (as explanatory variables) were carried out. The Statgraphics 
XVII software was employed and the linear fit tool was applied. The values of the properties for each alternative material (FR, FRR, SR and SRR) were considered a coefficient, obtained in relation to the reference traditional cellular concrete as follows:

$$
\beta_{x}=\frac{x_{m}}{x_{r}}
$$

where:

$\beta_{x}$ : coefficient for each property (where subscript $(\mathrm{x})$ can be: $\rho=$ natural density, $\mathrm{k}=$ thermal conductivity, $\rho_{\text {bulk }}=$ bulk density, $\phi_{0}=$ open porosity or $\phi_{c}=$ closed porosity) in the linear fit.

$x_{r}$ : property value obtained for the reference material (CA)

$x_{m}$ : property value obtained for each alternative material (FR, FRR, SR or SRR)

\section{RESULTS AND DISCUSSION}

The number, mean diameter and distribution of the pores obtained by FESEM, OM and the ImageJ software for samples CA, FR, FRR, SR and SRR are summarized in Figures 2-6, respectively.

The CA sample had many pores within the 300-600 $\mu \mathrm{m}$ size range, followed by the number of pores with sizes below $300 \mu \mathrm{m}$. A smaller proportion of pores had large diameters (from 600 to $3000 \mu \mathrm{m}$ ) and some pore dimensions exceeded $3000 \mu \mathrm{m}$ (Fig. 2). This sample presented an average pore diameter of $612 \mu \mathrm{m}$. The pore distribution of samples FR and FRR (Fig. 3-4) were similar to many pores whose size was under $300 \mu \mathrm{m}$ and the number of pores lowered within each range for larger sizes. The FRR sample had a small average number of pores/area (492 $\mu \mathrm{m})$ compared to the FR sample $(619 \mu \mathrm{m})$, which suggests less aeration reactivity when the commercial silicate was replaced with RHA (FRR sample). As in the CA sample, the FRR specimen had several pores whose size exceeded $3000 \mu \mathrm{m}$. For this reason, the average pore diameter for FRR $(649 \mu \mathrm{m})$ was larger than for FR $(513 \mu \mathrm{m})$.

The BFS samples SR and SRR (Fig. 5-6) displayed a more homogeneous pore distribution than the other cellular concretes herein studied. In these cases, many pore diameters were above $900 \mu \mathrm{m}$ compared to the CA, FR and FRR samples. Thus, the average pore diameters fell within the 804-819 $\mu \mathrm{m}$ range. The SRR samples had many pores bigger than $3000 \mu \mathrm{m}$, with a smaller average number of pores/area and a larger average diameter.

A trend in relation to the values of the number of pores/area and the average pore diameter exists. The samples with a smaller number of pores/area (SR and SRR) yielded high average diameter values. The sample with the smallest average pore diameter was FRR, which had the highest pores/area value. 
The best cellular concrete in terms of physical (natural density) and mechanical (compressive strength) properties (similarly to traditional systems) was represented by the ECC alternative system based on BFS (SRR samples, $611 \mathrm{~kg} / \mathrm{m}^{3}$ and 4.6 MPa). By reviewing the resultant pore system distribution of SRR, the air-void shape had no influence on the cellular concrete properties, which agrees with Nambiar and Ramamurthy (Nambiar and Ramamurthy 2007). A wide range of pore dimensions with a homogeneous distribution of pore diameters allowed us to obtain a matrix in which micropores were enclosed in the walls between macropores. Thus, a lower-density material can be obtained with no major strength loss. Conversely, the FR sample was the material with the highest density; as this GCC system had more pores/area, the diameter range of pores was narrower than it was for the other samples.

Table 5 shows the bulk density and porosity (total, open and closed porosities) assessed in each studied system.

When comparing bulk density with porosity in the alternative systems (FR, FRR, SR and SRR), a linear relation was experimentally obtained. High bulk density involves a high closed porosity and, consequently, a lower open porosity was obtained. This is logical if we consider that bulk density comes from considering the bulk volume, which involves the solid volume and the volume entrapped in the closed void of the material.

After comparing the materials, it can be stated that the total porosity of the CA sample was $80 \%$ and its closed porosity/open porosity ratio $\left(\Phi_{\mathrm{c}} / \Phi_{\mathrm{o}}\right)$ was 1.05 , which indicates that closed porosity was similar to open porosity. The FR sample had $66 \%$ total porosity with a $2.28 \Phi_{\mathrm{c}} / \Phi_{\mathrm{o}}$ ratio, so its relative closed porosity was much higher than in the CA sample. The FRR sample obtained $70 \%$ total porosity, with its $\Phi_{\mathrm{c}} / \Phi_{\mathrm{o}}$ between the CA and FR samples (1.62). The same total porosity of FRR was obtained for SR (70\%), but its $\Phi_{\mathrm{c}} / \Phi_{\mathrm{o}}$ ratio was 0.52 because the closed porosity was lower than the open porosity. Finally, for the SRR sample, total porosity was $66 \%$, which came close to the total porosity of FR but, as in the SR sample, this $\Phi_{\mathrm{c}} / \Phi_{\mathrm{o}}$ ratio was also below the unit $(0.65)$.

The results of the linear fit obtained from the statistical analysis are plotted in Figure 7 for natural density and in Figure 9 for thermal conductivity. These graphs reveal a positive linear dependence between density and closed porosity (Fig 7.a) and a negative linear dependence between natural density and open porosity (Fig 7.b). In both the resultant models, the p-value was lower than 0.05 , which means that a statistic significant relation between natural density and the explanatory variables (closed porosity and open porosity) existed, with a $95 \%$ confidence level. The R-squared statistic allowed to affirm that 
$92.17 \%$ of natural density variability was explained by the model fit assessed with closed porosity, and $96.74 \%$ by the model fit assessed with open porosity. Finally, a strong dependence of natural density with closed porosity and open porosity was found with a correlation coefficient of 0.96 and -0.98 , respectively.

The reduction in natural density for the systems with higher open porosity was most probably because open porosity consists in the volume of pores connected to the outside boundary of the material, which are filled with air. On the other extreme, the higher density of the systems when closed porosity is higher than open porosity can be explained by the increasing total volume of the solid matrix: there are many walls between closed pores. Furthermore, as observed in Figure 8, a direct relation appears between closed porosity and the number of the smallest size pore predominance (pore size $<300 \mu \mathrm{m}$ ). Thus the volume of the solid matrix in these materials was bigger and the natural density of the material increased. A linear fit was found when considering all the studied systems (traditional system, CA sample, was included in the fitting). The initial hypothesis of a high dependence between both variables was accepted with a p-value that equaled 0.02 and the R-squared statistic equaled $92 \%$.

Font et al.(Font et al. 2018) analyzed the physical properties of each alternative material (GCC and ECC systems) by its relative values in relation to traditional cellular concrete ones (TCC) to obtain the natural density $\left(\vartheta_{d}\right)$ and compressive strength $\left(\vartheta_{s}\right)$ ratio coefficients. The authors concluded that the relation between natural density and compressive strength was direct for the FCC samples and inverse for the BFS samples.

The models that describe the relation linking thermal conductivity with bulk density (Fig 9.a), closed porosity (Fig 9.b) and open porosity (Fig 9.c) showed an intense dependence relation, which has been commonly affirmed by other authors (Narayanan and Ramamurthy 2000b; Ramamurthy, Kunhanandan Nambiar, and Indu Siva Ranjani 2009). The model p-value was under 0.05 for the three linear fits that appeared. Thus, a statistically significant relation was found between thermal conductivity and the explanatory variables (closed porosity, open porosity, bulk density), with a 95\% confidence level. The statistic R-square allowed to affirm that the model fit explained $97.24 \%, 99.55 \%$ and $97.58 \%$ of natural density variation in relation to closed porosity, open porosity and bulk density, respectively. Finally, the correlation coefficients were -0.98 (negative linear dependence) for closed porosity as an explanatory variable, 0.99 (positive linear dependence) for open porosity as an explanatory variable and -0.98 
(negative linear dependence) for bulk density as an explanatory variable. This means a strong dependence of thermal conductivity on them.

\section{CONCLUSIONS}

The void-system configuration in the alternative alkali-activated cellular concretes (GCC) as well as ecocellular concretes (ECC) represents a primary influence on their functional properties (density, compressive strength and thermal conductivity).

A relation clearly links natural densities and compressive strengths with the void-system analyzed parameters (the average number of pores/area and the mean pore diameters). The development of a homogeneous void distribution, with non interconnected pores, regular shapes and continuous sizes, involves an alternative cellular concrete with lower natural density and enough matrix stability to achieve relatively high compressive strength.

The amount of pores/area can be associated with aeration effectiveness, while the size of the obtained pores indicates the reaction intensity. By comparing all the materials, the cellular concretes with more pores/area $(\mathrm{FR}>\mathrm{CA}>\mathrm{FRR}>\mathrm{SRR}>\mathrm{SR})$ achieved a more effective aerating reaction with a resulting matrix in which smaller pore size ranges predominated (pores smaller than $300 \mu \mathrm{m}$ : FR $>\mathrm{CA} \approx \mathrm{FRR}>\mathrm{SRR} \approx$ SR). The materials with fewer pores/area had bigger sized pores (pores above $3000 \mu \mathrm{m}$ : SRR $>$ SR $>$ FRR $\approx \mathrm{CA}>\mathrm{FR}$ ), which indicates a more aggressive and less effective aerating reaction.

A relation between bulk density and porosity was established: with an internal void system where the $\Phi_{\mathrm{c}} / \Phi_{\mathrm{o}}$ ratio was over the unit, and bulk density was higher than when the $\Phi_{\mathrm{c}} / \Phi_{\mathrm{o}}$ ratio was below the unit. Furthermore, closed porosity resulted in a direct relation with voids distribution where smaller sizes predominated. Finally, bulk density and porosity were confirmed as explanatory characteristics of the thermal conductivity in the alternative cellular concretes.

In general, greener cellular concrete alternatives, the ECC (FRR and SRR), have an internal void system with similar parameters to TCCs (CA).

\section{DATA AVAILABILITY STATEMENT}

Some or all data, models, or code that support the findings of this study are available from the corresponding author upon reasonable request.

\section{Acknowledgements}

The authors acknowledge the financial support from the Universitat Politècnica de València (UPV) through internal project GEOCELPLUS. The authors are especially grateful to Dr. Josefa L. Roselló 
314 Caselles for the recycled aluminum foil, and also to the Electronic Microscopy Service of the UPV.

315 Thanks also go to DACSA, BP Oil and Cementval for supplying the raw materials.

\section{Bibliography}

Akthar, F. K., and J. R.G. Evans. 2010. "High Porosity (> 90\%) Cementitious Foams.” Cement and Concrete Research 40(2): 352-58. http://dx.doi.org/10.1016/j.cemconres.2009.10.012.

Almalkawi, Areej T. et al. 2018. "Physio-Microstructural Properties of Aerated Cement Slurry for Lightweight Structures." Materials 11(4): 1-15.

Bai, Chengying et al. 2016. "High Strength Metakaolin-Based Geopolymer Foams with Variable Macroporous Structure." Journal of the European Ceramic Society 36(16): 4243-49. http://www.sciencedirect.com/science/article/pii/S0955221916303612.

Bremner, Theodore W, Philip M Carkner, Michael Healy, and Albert Litvin. 1997. "Guide for Precast Cellular Concrete Floor, Roof, and Wall Units." Manual of Concrete Practice: 2-6.

Colangelo, F. et al. 2018. "Mechanical and Thermal Properties of Lightweight Geopolymer Composites." Cement and Concrete Composites 86: 266-72.

Dolton, B, and C Hannah. 2006. "Cellular Concrete : Engineering and Technological Advancement for Construction in Cold Climates." : 1-11.

Ducman, V., and L. Korat. 2016. "Characterization of Geopolymer Fly-Ash Based Foams Obtained with the Addition of Al Powder or H2O2 as Foaming Agents." Materials Characterization 113: 20713. http://dx.doi.org/10.1016/j.matchar.2016.01.019.

Esmaily, H., and H. Nuranian. 2012. "Non-Autoclaved High Strength Cellular Concrete from Alkali Activated Slag." Construction and Building Materials 26(1): 200-206. http://dx.doi.org/10.1016/j.conbuildmat.2011.06.010.

Font, Alba et al. 2018. "New Eco-Cellular Concretes: Sustainable and Energy-Efficient Materials." Green Chemistry.

Kearsley, E.P., and P.J. Wainwright. 2001. "Porosity and Permeability of Foamed Concrete." Cement and Concrete Research 31(5): 805-12.

Nambiar, E. K Kunhanandan, and K. Ramamurthy. 2007. "Air-Void Characterisation of Foam Concrete." Cement and Concrete Research 37(2): 221-30.

Narayanan, N., and K. Ramamurthy. 2000a. "Microstructural Investigations on Aerated Concrete." Cement and Concrete Research 30(3): 457-64. 
- 2000b. "Structure and Properties of Aerated Concrete: A Review." Cement and Concrete Composites 22(5): 321-29.

Narayanan, N, and K Ramamurthy. 2000c. "Prediction Models Based on Gel-Pore Parameters for Compressive Strength of Aerated Concrete.” 2(December): 206-12.

Othuman, Md Azree, and Y. C. Wang. 2011. "Elevated-Temperature Thermal Properties of Lightweight Foamed Concrete." Construction and Building Materials 25(2): 705-16. http://dx.doi.org/10.1016/j.conbuildmat.2010.07.016.

Panesar, D. K. 2013. "Cellular Concrete Properties and the Effect of Synthetic and Protein Foaming Agents." Construction and Building Materials 44: 575-84. http://dx.doi.org/10.1016/j.conbuildmat.2013.03.024.

Pinilla Melo, Javier, Alberto Sepulcre Aguilar, and Francisco Hernández Olivares. 2014. "Rheological Properties of Aerated Cement Pastes with Fly Ash, Metakaolin and Sepiolite Additions." $\begin{array}{llll}\text { Construction } & \text { and } & \text { Building } & \text { Materials }\end{array}$ http://dx.doi.org/10.1016/j.conbuildmat.2013.05.082.

Ramamurthy, K., E. K. Kunhanandan Nambiar, and G. Indu Siva Ranjani. 2009. “A Classification of Studies on Properties of Foam Concrete." Cement and Concrete Composites 31(6): 388-96. http://dx.doi.org/10.1016/j.cemconcomp.2009.04.006.

Stolz, Jonathan, Yaman Boluk, and Vivek Bindiganavile. 2018. "Mechanical, Thermal and Acoustic Properties of Cellular Alkali Activated Fly Ash Concrete." Cement and Concrete Composites 94(August): 24-32. https://doi.org/10.1016/j.cemconcomp.2018.08.004.

Topçu, Ilker Bekir, and Tayfun Uygunoğlu. 2007. "Properties of Autoclaved Lightweight Aggregate Concrete.” Building and Environment 42(12): 4108-16.

Wee, Tiong-Huan, Daneti Saradhi Babu, Tamilselvan T, and Hwee-Sin Lim. 2006. "Air-Void System of Foamed Concrete and Its Effect on Mechanical Properties." ACI Materials Journal 103(0889325X): 45-52. http://scholarbank.nus.edu.sg/handle/10635/84515.

Xuan, Dongxing, Pei Tang, and Chi Sun Poon. 2019. "MSWIBA-Based Cellular Alkali-Activated Concrete Incorporating Waste Glass Powder.” Cement and Concrete Composites 95(August 2018): 128-36. https://doi.org/10.1016/j.cemconcomp.2018.10.018.

Yang, Keun Hyeok, Kyung Ho Lee, Jin Kyu Song, and Min Ho Gong. 2014. "Properties and Sustainability of Alkali-Activated Slag Foamed Concrete." Journal of Cleaner Production 68: 
Zhang, Zuhua, John L. Provis, Andrew Reid, and Hao Wang. 2015. "Mechanical, Thermal Insulation, and Concrete Composites 62: 97-105. http://dx.doi.org/10.1016/j.cemconcomp.2015.03.013.

Table 1. Composition and selected properties of the different cellular concretes(Font et al. 2018).

\begin{tabular}{|c|c|c|c|c|c|c|c|}
\hline & Precursor & $\begin{array}{c}\text { Aerating } \\
\text { agent }\end{array}$ & Liquid Phase & Mixtures & $\begin{array}{l}\text { Density } \\
\left(\mathrm{kg} / \mathrm{m}^{3}\right)\end{array}$ & $\begin{array}{c}\text { Compressive } \\
\text { strength } \\
\text { (MPa) }\end{array}$ & $\begin{array}{c}\text { Thermal } \\
\text { conductivity } \\
(\mathrm{W} / \mathrm{mK})\end{array}$ \\
\hline TCC & OPC & A & Water & CA & $618 \pm 2$ & $6.5 \pm 0.4$ & $0.182 \pm 0.001$ \\
\hline GCC & FCC & & $\mathrm{NaOH}+\mathrm{WG}$ & FR & $813 \pm 2$ & $4.3 \pm 0.4$ & $0.083 \pm 0.003$ \\
\hline & BFS & RAF & & SR & $474 \pm 4$ & $2.6 \pm 0.2$ & $0.281 \pm 0.007$ \\
\hline ECC & FCC & & $\mathrm{NaOH}+\mathrm{RHA}$ & FRR & $782 \pm 4$ & $\begin{array}{l}3.2 \pm 0.3 \\
4.6 \pm 0.3\end{array}$ & $0.113 \pm 0.005$ \\
\hline
\end{tabular}

Table 2. Materials and its origin

\begin{tabular}{ll}
\hline \hline Ordinary Portland Cement (OPC) & Lafarge S.A \\
\hline Fluid catalytic cracking residue (FCC) & BP Oil Company \\
\hline Blast furnace slag (BFS) & Cementval S.A \\
\hline Rice husk ash (RHA) & DACSA S.A \\
\hline Commercial aluminum powder (A) & Schlenk Metallic Pigments GmbH \\
\hline Recycled aluminum foil RAF & Department of Agricultural Forest Ecosystems at \\
& the Universitat Politècnica de València \\
\hline NaOH (pellets - 98\% purity) & Panreac S.A \\
\hline WG $\left(8\right.$ wt $\% \mathrm{Na}_{2} \mathrm{O}, 28 \%$ wt $\% \mathrm{SiO}_{2}$ and $64 \%$ wt\% & Merck-Spain \\
$\left.\mathrm{H}_{2} \mathrm{O}\right)$ & \\
\hline
\end{tabular}

Table 3. Chemical compositions of OPC, FCC, BFS and RHA (wt\%). 


\begin{tabular}{cccccccccccccc}
\hline OPC & 20.80 & 4.60 & 4.80 & 65.60 & 1.20 & 1.70 & 1.00 & 0.07 & - & - & - & 0.23 \\
\hline FCC & 47.76 & 49.26 & 0.60 & 0.11 & 0.17 & 0.02 & 0.02 & 0.31 & 0.01 & 1.22 & - & 0.53 \\
BFS & 30.53 & 10.55 & 1.29 & 40.15 & 7.43 & 1.93 & 0.57 & 0.87 & 0.26 & 0.89 & - & 5.53 \\
\hline RHA & 85.58 & 0.25 & 0.21 & 1.83 & 0.5 & 0.26 & 3.39 & - & 0.67 & - & 0.32 & 6.99 \\
\hline
\end{tabular}

*Loss on ignition

Table 4. Overview of the materials and doses to the specimen's manufacture.

\begin{tabular}{|c|c|c|c|c|c|c|c|}
\hline & \multicolumn{3}{|c|}{ Solid phase } & \multicolumn{4}{|l|}{ Liquid phase } \\
\hline & \multirow[t]{2}{*}{ Precursor } & Aerating & Dose & & $\mathrm{w} / \mathrm{b}$ & \multirow{2}{*}{$\mathrm{SiO}_{2} / \mathrm{Na}_{2} \mathrm{O}$} & \multirow{2}{*}{$\begin{array}{l}\mathrm{Na}^{+} \text {molality } \\
\text { (3) }\end{array}$} \\
\hline & & agent & \multicolumn{2}{|l|}{$(\mathrm{wt} \%)$} & (2) & & \\
\hline $\mathrm{CA}$ & $\mathrm{OPC}^{(1)}$ & $\mathrm{A}$ & & Water & 0.50 & - & \multirow[t]{2}{*}{-} \\
\hline FR & FCC & \multirow{4}{*}{ RAF } & & Water/NaOH/WG & 0.60 & \multirow{4}{*}{1.70} & \\
\hline FRR & & & $2 \%$ & Water/NaOH/RHA & 0.70 & & \multirow{3}{*}{7.50} \\
\hline SR & \multirow[t]{2}{*}{ BFS } & & & Water/NaOH/WG & 0.35 & & \\
\hline SRR & & & & Water/NaOH/RHA & 0.45 & & \\
\hline \multicolumn{8}{|c|}{${ }^{1} \mathrm{OPC}=\mathrm{CEM} \mathrm{I}-52.5 \mathrm{R}$} \\
\hline \multicolumn{8}{|c|}{${ }^{2} \mathrm{w} / \mathrm{b}=$ water/binder ratio } \\
\hline${ }^{3} \mathrm{Na}^{+}$ & olality $=r$ & of sodiu & $\mathrm{kg}$ of & ter. & & & \\
\hline
\end{tabular}

Table 5. Values of bulk density and porosity (total, $\Phi$ t; open, $\Phi$; closed, $\Phi c$ ) obtained from hydric tests.

\begin{tabular}{lcccc} 
& Bulk density & \multicolumn{3}{c}{ Porosity (\%) } \\
\cline { 3 - 5 } & $\left(\mathrm{kg} / \mathrm{m}^{3}\right)$ & 80 & 39 & 41 \\
\hline CA & $614 \pm 1$ & 69 & 21 & 48 \\
\hline FR & $797 \pm 2$ & 70 & 27 & 44 \\
FRR & $740 \pm 2$ & 70 & 46 & 24 \\
SR & $584 \pm 2$ & 66 & 40 & 26 \\
\hline
\end{tabular}




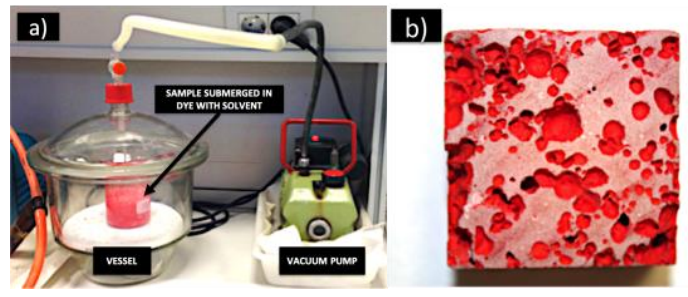

- Fig. 1. Specimen preparation for the ImageJ analyses: a) sample immersed in color solution, connected to a vacuum pump; b) the impregnated internal surface of samples ( $4 \mathrm{x} 4 \mathrm{~cm}^{2}$ section).

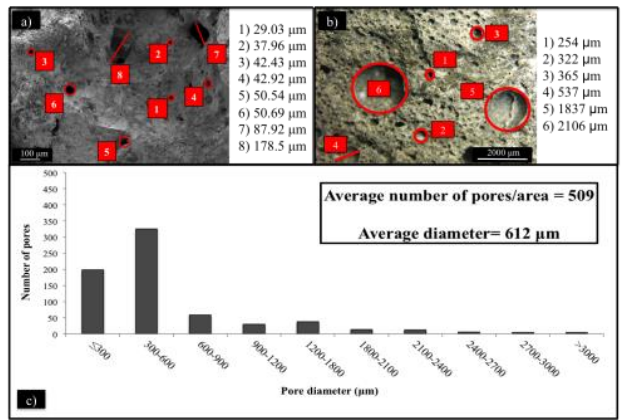

- Fig 2. Pore system characterization of CA: a) FESEM micrograph at 100x magnifications with pore sizing; b) OM image at 8x magnifications with pore sizing; c) pore diameter distribution in the $16-\mathrm{cm}^{2}$ area.

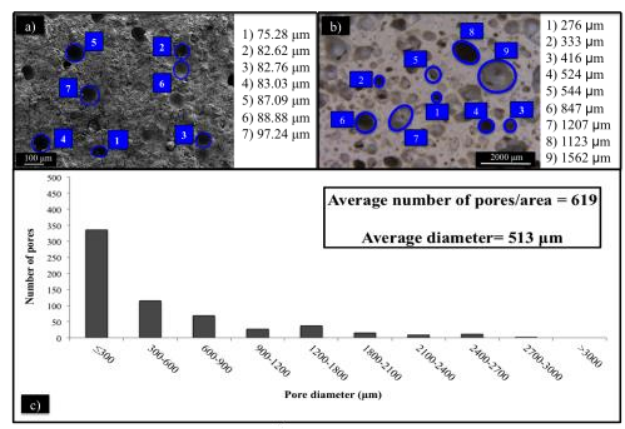

- Fig 3. Pore system characterization of FR: a) FESEM micrograph in 100x magnifications with pore sizing; b) OM image in $8 \mathrm{x}$ magnifications with pore sizing; c) pore diameter distribution in the $16-\mathrm{cm}^{2}$ area. 


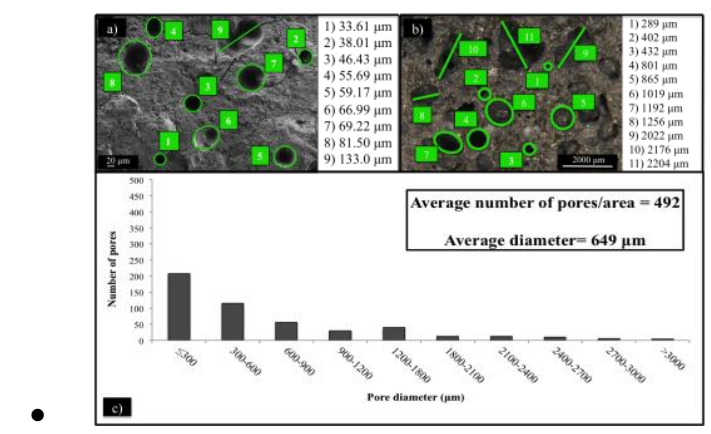

- Fig 4. Pore system characterization of FRR: a) FESEM micrograph in 200x magnifications with pore sizing; b) OM image in $8 \mathrm{x}$ magnifications with pore sizing; $\mathrm{c}$ ) pore diameter distribution in the $16-\mathrm{cm}^{2}$ area.

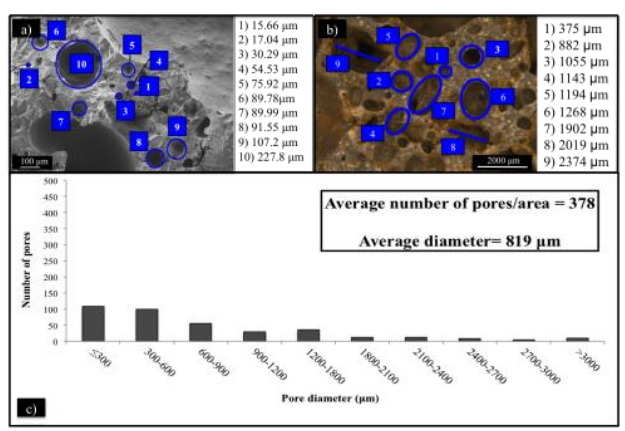

- Fig 5. Pore system characterization of SR: a) FESEM micrograph in 100x magnifications with pore sizing; b) OM image in $8 \mathrm{x}$ magnifications with pore sizing; c) pore diameter distribution in the $16-\mathrm{cm}^{2}$ area.

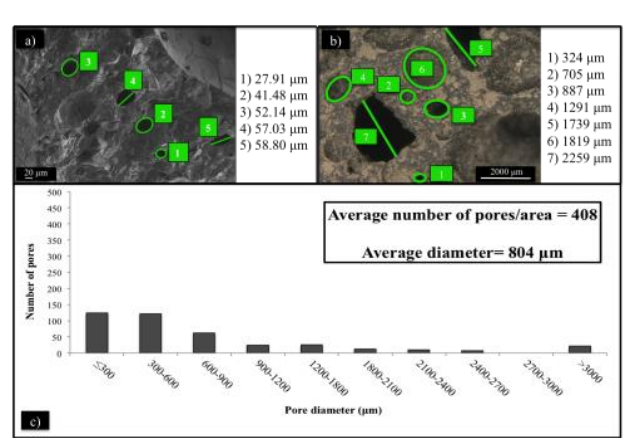

- Fig 6. Pore system characterization of SRR: a) FESEM micrograph in 200x magnifications with pore sizing; b) OM image in $8 \mathrm{x}$ magnifications with pore sizing; c) pore diameter distribution in the $16-\mathrm{cm}^{2}$ area. 
a)

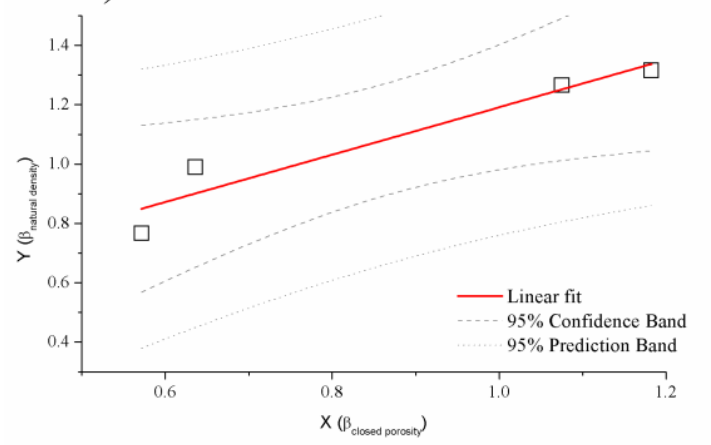

b)

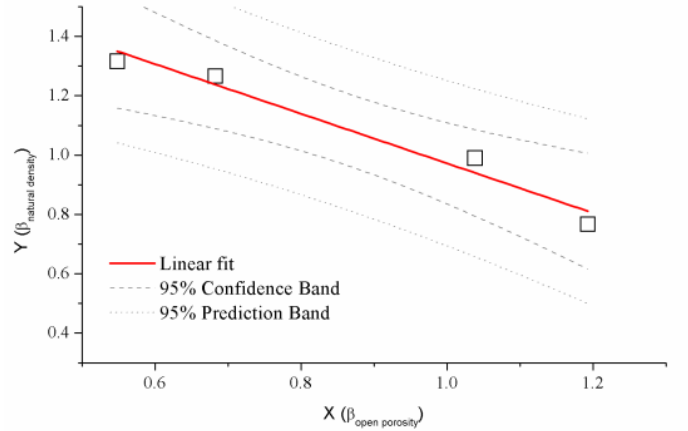

406

- Fig 7. Linear fit model for: a) natural density (dependent variable) and closed porosity

408

(explanatory variable); and b) natural density (dependent variable) and open porosity (explanatory variable).

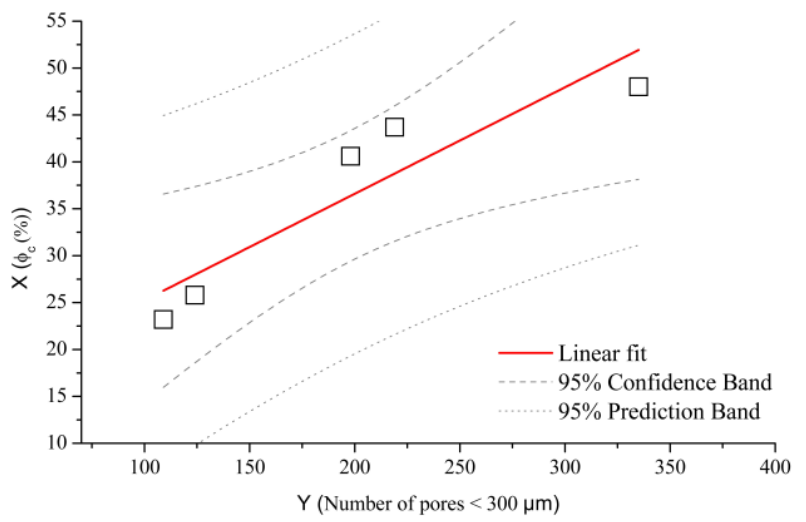

- Fig 8. Linear fit model for closed porosity (dependent variable) and number of pores smaller than $300 \mu \mathrm{m}$ (explanatory variable). 
a)

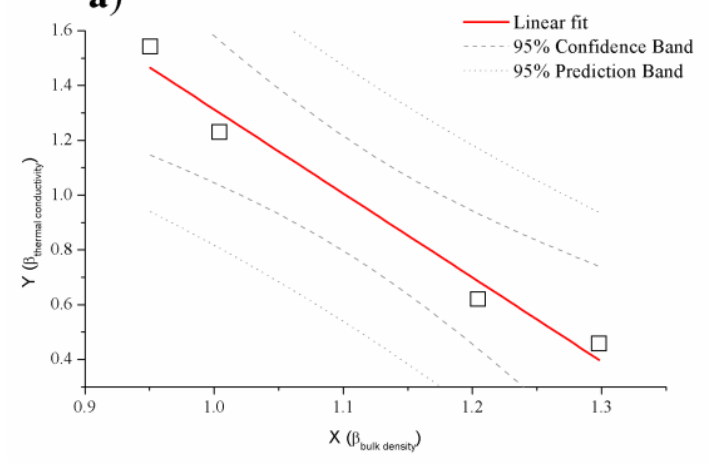

413

b)

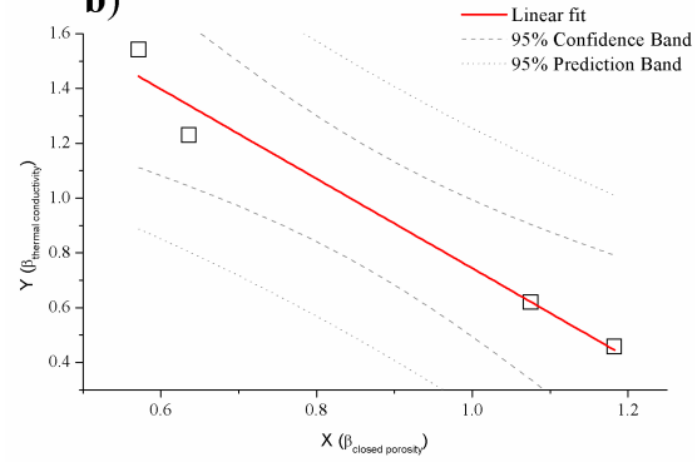

414

c)

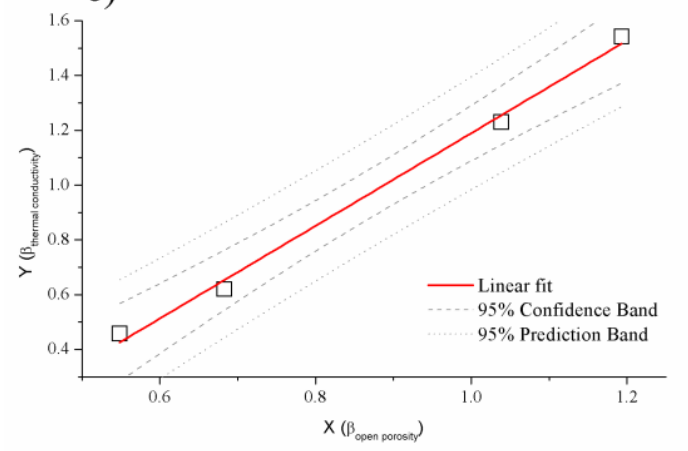

415

416 - Fig 9. Linear fit models for: a) thermal conductivity (dependent variable) and bulk density (explanatory variable); b) thermal conductivity (dependent variable) and closed porosity (explanatory variable); c) thermal conductivity (dependent variable) and open porosity (explanatory variable) 